\author{
Yu.F. Vasyuchkov*, M.A. Fedorova*
}

\title{
SYNTHETIC GAS PRODUCTION DURING UNDERGROUND GASIFICATION OF COAL SEAMS
}

In the countries where natural gas reserves are absent or limited it is very important to use natural coal for production of synthetic gas extracted from coal seams. The experience of the production process named as underground coal gasification (UCG) is counted many years. Nevertheless the wide employment of the process in gas industry doesn't take place today. A fault for this is absent exact knowledge about temperature distribution in a fire hearth of the coal seam.

Besides it is important because today there are environment clean and energy effective technologies for a coal extraction on the base of the coal and gas and electricity complexes $[1,2,3]$. This article gives interpretation for UCG process. Scheme of the fire health in coal seam's channel is cited in Figure 1.

Black colour means the coal seam in a vertical section along strike and red colour is fire of health with temperature of $800-1200^{\circ} \mathrm{C}$ and yellow colour is lower temperature in fresh air flow with temperature $500-800^{\circ} \mathrm{C}$ and blue colour is the air flow about crushed roof rocks. Yellow arrow shows stream of convection heat flow from the fire health deep into the seam. Although the distribution of the zones is approximate (turbulence in the flow takes place) this model allows you to evaluate distribution of temperature during underground gasification process in coal mass and to obtain more specific information about a deep of the coal seam warming-up.

For start point we shall take a coal wall of the fire channel and shall decide a task of thermal conductivity of the coal seam in stationary conditions for the temperature in fire health of $1000 \mathrm{~K}$. Limited conditions we shall take next: coefficient of thermal conductivity

* Science and Research Technological University Moscow Institute of Steel and Alloys, Moscow Mining Institute 
$\lambda=0.14 \mathrm{Wt} / \mathrm{m} \cdot \mathrm{K}$ and coefficient of a heat emission $\alpha=0.1 \mathrm{Wt} / \mathrm{m}^{2} \cdot \mathrm{K}$. The meaning of coefficient $\alpha$ we shall to decide the task for a coal parallelepiped with a square $1 \mathrm{~m}^{2}$ and a perimeter $4 \mathrm{~m}$ and a heat exchange between borders of the parallelepiped is absent. Thus we have monaxonic task by way the mathematical term.

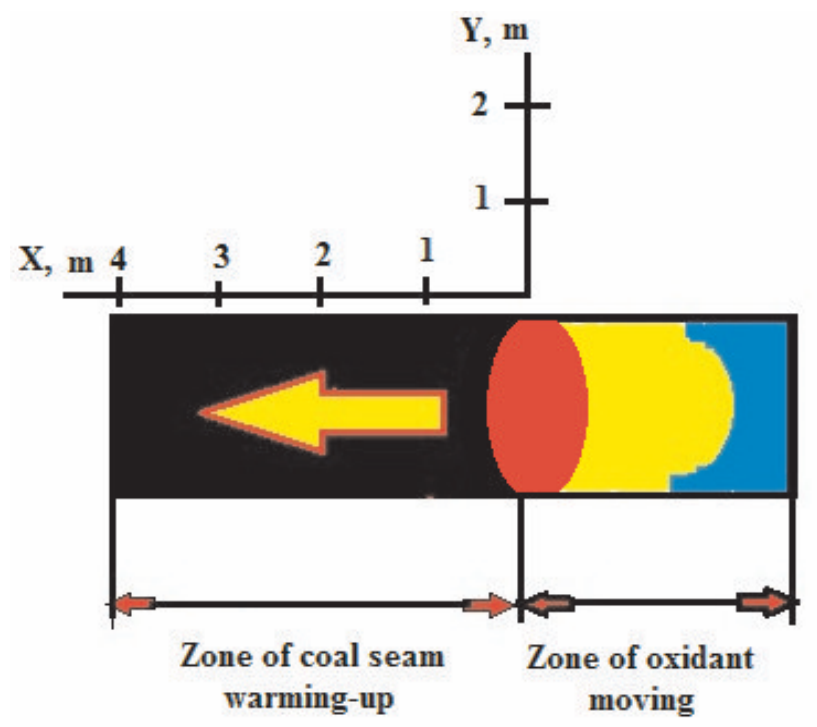

Fig. 1. Scheme of coal seam and distribution of temperature zones in a fire face during UCG

From theory of thermal conductivity the start equation for being conditions is

$$
\frac{d^{2} T}{d x^{2}}=\frac{k}{D} \cdot T
$$

where:

$T$ - temperature of the coal seam $[\mathrm{K}]$,

$k, D$ - indexes of coal seam, which are characteristic for thermal and physical properties of the one.

Input symbols

$$
k / D=a^{2}=\alpha \cdot P_{y} /\left(\lambda \cdot S_{y}\right)
$$

where $P, S$ - perimeter [m] and square of the section of the single coal parallelepiped in the coal seam $\left[\mathrm{m}^{2}\right]$. They are $P=4 \mathrm{~m}$ and $S=1 \mathrm{~m}^{2}$.

In the case $a=\sqrt{\frac{\alpha \cdot P}{\lambda \cdot S}},\left[\mathrm{~m}^{-1}\right]$. Equation (1) we decide on a base method conformal transformation Laplace. 
Taking into account (2) equation (1) will be converted in connection of original function and representation of the one and will has next view

$$
T^{\prime \prime}(x)-a^{2} \cdot T(x)=0
$$

Using tables of the conformal transformation for original function (3) we shall find next representation

$$
p^{2} y-p^{2} x_{0}-p x_{1}-a^{2} y=0
$$

Deciding (4) concerning $y$, we shall have (5)

$$
\mathrm{Y}(p)=x_{0} \frac{p^{2}}{\left(p^{2}-a^{2}\right)}+\frac{x_{1}}{a} \frac{p \cdot a}{\left(p^{2}-a^{2}\right)}
$$

On the base (5) for the representation $T=f(x)$ may find a decision of our task

$$
T(x)=\frac{T_{2} \cdot \operatorname{sh}(a \cdot x)+T_{1} \cdot \operatorname{sh}(a \cdot(l-x))}{\operatorname{sh}(a \cdot l)}
$$

where:

$T_{2}$ - temperature in the fire health of the coal seam [K];

$T_{1}$ - temperature in the end of length of the single coal parallelepiped $l[\mathrm{~m}],[\mathrm{K}]$; $\operatorname{sh}(a \cdot x)$ - hyperbolic sinus of the dimensionless expression $(a \cdot x)$.

Further we make numeric modeling for next limited conditions:

$x=0$ (a wall of fire channel in the coal seam) $T_{0}=1000 \mathrm{~K}$;

$x=l$ (the end of coal parallelepiped into a depth of the coal seam channel) $T_{l}=100 \mathrm{~K}$;

$$
a=\sqrt{\frac{\alpha \cdot P}{\lambda \cdot S}}=\frac{0,1 \cdot 4}{0,14 \cdot 1}=1,691 / \mathrm{m}
$$

Output computation (6) is cited in Table 1.

Results of numerical simulation earnestly prove that maximum losses are had on distance $0.5-1 \mathrm{~m}$ from the coal seam wall into the depth of the one. Relation $T=f(x)$ has a view of decreasing exponent and has polynomial character (Fig. 2).

From industry using processes it may be more advanced like Lurgy gasification into a layer of hard fuel with steam and oxygen flow [4, 5]. In general this reaction is reversible but it is need to observe clear terms. Thus in the underground conditions we must consider both distribution of temperatures into coal seam and thermal and dynamical conditions of the chemical reactions a carbon with the oxidant and water steam. 
Table 1

Numerical simulation of thermal warming-up of the coal seam zone in the UCG process

\begin{tabular}{|c|c|c|c|c|c|}
\hline$x[\mathrm{~m}]$ & $a \cdot x$ & $\operatorname{sh}(a \cdot x)$ & $a \cdot(l-x)$ & $\operatorname{sh}(a \cdot(l-x))$ & $T(x)$ \\
\hline 0 & 0 & 0 & 3.380 & 14.668 & 1000.0 \\
\hline 0.25 & 0.423 & 0.436 & 2.957 & 9.594 & 657.0 \\
\hline 0.50 & 0.845 & 0.949 & 2.535 & 6.269 & 433.8 \\
\hline 0.75 & 1.268 & 1.636 & 2.112 & 4.072 & 288.8 \\
\hline 1.00 & 1.690 & 2.617 & 1.690 & 2.617 & 196.3 \\
\hline 1.25 & 2.112 & 4.072 & 1.268 & 1.636 & 139.3 \\
\hline 1.50 & 2.535 & 6.269 & 0.845 & 0.949 & 107.4 \\
\hline 1.75 & 2.957 & 9.594 & 0.423 & 0.436 & 101.2 \\
\hline 2.00 & 3.380 & 14.668 & 0 & 0 & 100 \\
\hline
\end{tabular}

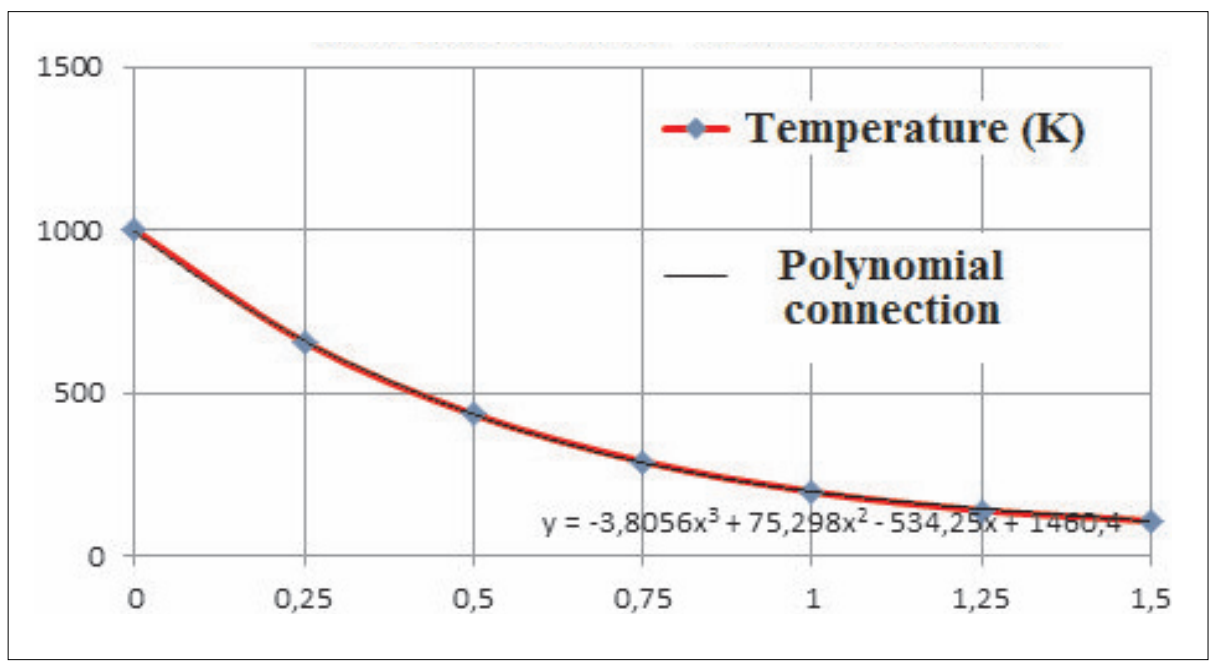

Fig. 2. Temperature $[\mathrm{K}]$ in function a distance $[\mathrm{m}]$ into coal massive from a fire health

\section{REFERENCES}

[1] Vasyuchkov Yu.F.: Extraction of coal reserves by shaftless method with underground combustion coal seam and using thermal and/or power generation on the same coal mine fields. Proceedings of Russian Conference "Complex learning and extraction economic minerals". Russia, Novocherkask, 1995, 28-32. 
[2] Vasyuchkov Yu.F., Vorobjev B.M.: Concept of resource saving technology for haftless extraction of coal fields. Russia, Moscow, MSMU, MIAB, 1996.

[3] Kaplan S.: Power Plants: Characteristics and Costs, Washington. CRS Report for Congress. 2008, November 13, 97 (total volume 108 pp).

[4] Redman E.: Comparisions Underground and Surface Coal Gasification. Houston, USA, 2007. www.hellerehram.com

[5] Vasyuchkov Yu.F., Bykova M.Yu., Vasyuchkov M.Yu.: Science Principles for Concept-Project of Combined coal and Gas and Electrical blocks. AGH Drilling, Oil, Gas, No. 30, 2013, 261-26. 